of giving health talks to factory staffs during lunchhour breaks. Several factory managements were approached and the response was most encouraging. Four talks were given by the Medical Officer of Health to approximately 2,400 factory workers, the attendances ranging from 400 to 1,000 . A new drive was made in 1955, and in the first six months of the year fourteen talks were given in factories on subjects including influenza, coughs and colds ; cancer ; mass minjature radiograpby; nutrition; accident prevention and sepsis. With the outbreak of poliomyelitis in the beginning of July 1955, a new stimulus was given to the work. Most factories were only too willing to provide facilities for a talk on this subject, and some of them approached the health department direct. Altogether, up to the end of October, ninetysix talks were given in eighty factories to 23,500 workers. The number in the audience varied from 20 to 4,000 , with the majority in the range of 100 to 200 . Co-operation with the factory management was not easy at first. Personal contact with the personnel or works manager was necessary.

\section{Row-crop System for Grass}

THE technique of growing grass in wide rows instead of in broadcast stands was first developed for grass, chiefly cocksfoot, intended for sced production. Coupled with heavy dressings of nitrogen, part of which was applied in late summer, this system was found to give increased yields of seed and, incidentally, to prolong the growing season well into the winter. With the post-war drop in seed prices, the emphasis has changed and the interest now lies in how the row-crop system may best be used by the grazier. Some account of Scottish experiences with the method is given by I. V. Hunt in an article entitled "Rowerop Grass", published in tho autumn number of Scottish Agriculture (Edinburgh : H.M.S.O.; 1s.). The grass is sown in strips 12-28 in. apart, with jnter-row cultivation in the initial stages. In the summer the crop is grazed or cut for hay, silage or dried grass. Fertilizer is then applied and later growth kept for winter grazing. Cocksfoot has so far proved the most suitable grass; but trials are in progress with timothy, meadow fescue and perennial ryegrass. A seed crop should be possible from cocksfoot and meadow fescue with. out prejudicing the winter grazing, but timothy would ripen too late. Other promising features of the system are the reduction in waste from treading, winter burning, or rotting, earlier growth in spring and considerable reduction in the cost of seed. The method is still in the experimental stage; but it has steadily gained favour on English and Welsh farms and may prove of special use in Scotland where the grazing season is normally short.

\section{Cultivation of Lucerne in Britain}

THE acreage under lucerne in England and Wales has now reached some 112,000 acres, half of which lies in East Anglia, Kent and Lincolnshire. The crop requires skill in management and makes heavy demands on soil fertility; but its drought-resistant properties and vigorous growth during the summer make it a valuable plant for the establishment of leys, and it can be profitably grown in all parts of Britain. Memoir No. 1 of the Grassland Research Institute, entitled "Lucerne Investigations 19441953" (pp. 81 ; from the Institute, Hurley, near Maidenhead, 1955 ; $10 s$.), should help farmers to utilize this crop better, for it gives the results of critical field experiments carried out by the Institute and the National Agricultural Advisory Service in different parts of the country. Information regarding the different strains of lucerne is provided in an article contributed by the National Institute of Agricultural Botany, Cambridge; from the trials at the Grassland Research Institute, the early long. season type appears to have given the most promising results so far. Much attention is devoted to the subject of management, including that of leys where the lucerne is associated with different companion grasses. Remarkable differences in yield can be obtained by changes in timing the cuts, autumn being a specially critical period. A useful bibliography is included in the memoir.

\section{Germination Regulation in Desert Seeds}

THE regulation of germination in the seeds of the desert leguminous species Colutea istria Mill. has been investigated in some detail by D. Koller and M. Negbi (Bull. Res. Council Israel, Sect. D, Botany, $5 D, 1,73 ; 1955)$. 'The seeds were found to be largely impermeable to water. This could be remedied ejther by treatment with concentrated sulphuric acid, or by vigorous shaking in a glass jar. Swelling was more rapid after the former treatment. It was found that, whereas acid treatment removes impermeability by acting all over the surface of the seed coat, the shaking did so only in the micropylar region. Permeable seeds germinated equally well in light and in dark, and their germination was in. sensitive to temperature between $20^{\circ}$ and $30^{\circ} \mathrm{C}$. Seedling growth in dark exceeded that in light. The two seed samples investigated, which were collected in different years and locations, differed widely in germination. This was apparent]y caused by different degrees of maturity which the embryos had attained before fruit ripening. Two separate coats surround the embryo. The inner coat has no influence on germination in the fully 'ripe' sample, but in the 'unripe' sample it affords the embryo some kind of protection against decay. The outer coat in both samples contains a water-soluble growth inhibitor, which retards embryo growth. Successful reseeding of depleted desert pastures was carried out with this species in the Negev Highlands.

\section{Nuclear Differences in Onion Root Tissue}

IN former years it was generally assumed that the colls of the various tissues of a higher plant had nuclei the constitution of which was identical with that of the fertilized ovum. Some recent investigations have shown, however, that the nuclei in all cells are not alike. A. L. Chouinard (Canad. J. Bot., 33 , No. 6,$628 ; 1955$ ) has contributed to this topic by observing the nuclear differences in onion (Allium cepa) root tissues as revealed by the induction of mitosis with indoleacetic acid. Treatment with this growth substance was used for stimulating mitosis in differentiated tissues of Allium cepa roots in order to establish whether nuclear differences, specifically in chromosome number, exist normally and are merely revealed by treatments, or whether these nuclear differences are produced by the treatment. With the concentrations of indoleacetic acid and durations of treatment used, evidence was obtained that chromosome number differences exist in the differentiated tissues of onion root prior to any treatment, and that the appearance of these differences after treatment is a matter of revelation and not of causation. The evidence obtained in these investigations comes 